\title{
CORPO, COTIDIANO E REPRODUÇÃ̃̃ CONSIDERAÇÕES SOBRE O NEOLIBERALISMO A PARTIR DE SILVIA FEDERICI
}

\author{
Nathan Menezes Amarante Teixeira ${ }^{1}$ \\ Universidade do Estado do Rio de Janeiro (UERJ) \\ (D) https://orcid.org/0000-0001-7292-6177 \\ E-mail: nathanmateixeira@gmail.com
}

\section{RESUMO:}

Este trabalho busca apresentar em detalhes as considerações de Silvia Federici sobre o neoliberalismo, tendo como centro de discussão a forma em que as noções de corpo, reprodução e cotidiano são mobilizados pela autora. Nesta perspectiva, será apresentada uma condição materialista do modo de vir a ser possível dos indivíduos na medida em que somos fundamentalmente corpos cuja ligação à totalidade social se dá mediada pelo enraizamento na particularidade situada do cotidiano. Assim, dialogando ainda com outros autores tais como Simone de Beauvoir, Rosa Luxemburgo e Henri Lefebvre, trata-se de apresentarmos o desenvolvimento de uma perspectiva que coloca a reprodução cotidiana da vida como uma força produtiva central para o ser social e, sedimentada como hábitos no corpo, produz e reproduz modos de ser, base a partir da qual as considerações sobre a lógica neoliberal serão compreendidas, assim como ficará marcada a importância da abordagem crítica feminista de Federici em relação ao modo de produção capitalista.

PALAVRAS-CHAVE: Silvia Federici; Reprodução; Corpo; Cotidiano; Neoliberalismo.

\section{BODY, DAILY LIFE AND REPRODUCTION: CONSIDERATIONS ON NEOLIBERALISM FROM SILVIA FEDERICI}

\begin{abstract}
:
This paper seeks to present in detail Silvia Federici's considerations about neoliberalism, having as a center of discussion the way in which the body, reproduction and daily life are mobilized by the author. In this perspective, a materialistic condition of the way of becoming possible of individuals will be presented to the extent that we are fundamentally bodies whose connection to social totality is mediated by rooting in the situated particularity of daily life. Therefore, also dialoguing with other authors such as Simone de Beauvoir, Rosa Luxemburgo and Henri Lefebvre, it is a question of presenting the development of a perspective that places the daily reproduction of life as a central productive force for the social being and, sedimented as habits in the body, produces and reproduces ways of being, the basis from which considerations about neoliberal logic will be understood, and thus, the importance of Federici's feminist critical approach to the capitalist mode of production will be marked.
\end{abstract}

KEYWORDS: Silvia Federici; Reproduction; Body; Daily Life; Neoliberalism.

\footnotetext{
${ }^{1}$ Doutor(a) em Filosofia pela Universidade Federal do Rio de Janeiro (UFRJ), Rio de Janeiro - RJ, Brasil. Pós-doutorando(a) na Universidade do Estado do Rio de Janeiro (UERJ), Rio de Janeiro - RJ, Brasil. Bolsista do(a): Fundação Carlos Chagas Filho de Amparo à Pesquisa do Estado do Rio de Janeiro ( FAPERJ), Rio de Janeiro - RJ, Brasil.
}

TEIXEIRA, Nathan Menezes Amarante. Corpo, cotidiano e reprodução: considerações sobre o neoliberalismo a partir de Silvia Federici. Griot : Revista de Filosofia, Amargosa - BA, v.21 n.3, p.218-235, outubro, 2021. 
Esta pesquisa tem por base o pensamento de Silvia Federici apresentado em suas diferentes obras, especificamente na sua crítica ao capitalismo em geral e à sua forma neoliberal em particular, onde o corpo e a dimensão da reprodução são pontos fundamentais de estruturação dessa crítica assim como, por consequência, as bases para recolocar teoricamente o princípio dos comuns $^{2}$ e então para que este "se traduza em um projeto político coerente" (FEDERICI, 2019b, p. 103). A especificidade da sua mobilização em nome de uma revalorização da base material comum da existência se mostra significativa justamente por assumir " [...] as atividades do dia a dia, através das quais produzimos nossa existência [...]" (FEDERICI, p. 2019a, p. 19) como o ponto a partir do qual pode recolocar a análise da racionalidade própria do capital. Deste modo, assumir esta base aqui significa, primeiramente, objetivar em suas especificidades detalhando as considerações de Silvia Federici acerca dos pontos acima levantados, e, em seguida, compreender o seu posicionamento contrário à "[...] ampliação do formato de mercadoria a todas as esquinas da usina social promovida pelo neoliberalismo [...]" (FEDERICI, p. 2019b, p. 104). Por sua vez, conforme o andamento do texto, colocaremos a perspectiva de Federici em diálogo com outros autores, visando desdobrar maiores considerações a partir de sua base argumentativa.

Tomemos então como ponto de partida da discussão a forma como Federici coloca o corpo em seu livro intitulado Beyond the periphery of the skin. É fundamental, portanto, a ideia apresentada diretamente pela autora de que sua perspectiva assume como central que o corpo não é “[...] constituído como uma mônada Leibneziana, sem janelas ou portas [...]" (FEDERICI, p. 2020 , p. 5) posto que ele sempre se "[...] expande para além das periferias da sua pele [...]" (FEDERICI, 2020, P. 5), ou seja, trata-se da afirmação de que o modo de ser do corpo sempre depende diretamente das condições materiais de nossas vidas e, portanto, que nossos corpos são constituídos continuamente por relações com o mundo social circundante. Por conta disso é necessário o reconhecimento de que:

Não há mudança social, nem inovação cultural ou política que não seja expressa através do corpo, nenhuma prática econômica que não seja aplicada a ele. [de modo que] [...] a principal razão pela qual nós devemos falar do corpo se dá pelo fato de que repensar como o capitalismo transformou nossos corpos em força de trabalho nos ajuda a colocar em contexto as crises às quais nossos corpos são continuamente entregues [...] (FEDERICI, 2020 , p. 76).

Assim, há um destaque dado à dependência do corpo ao modo de ser social, ou seja, ao fato de que a continuidade materialmente dada da existência diária dos corpos está relacionada à especificidade que a totalidade social assume historicamente como certo modo de produção e reprodução de si enquanto totalidade. A importância disto consiste em que, dentro deste recorte, nossos corpos se apresentam como dotados de um complexo de necessidades, desejos e capacidades que se mostram como uma "[...] estrutura acumulada [...]" (FEDERICI, 2020, p. 77, grifo meu) que um desenvolvimento histórico “ [...] sedimentou em nós [...]" (FEDERICI, p. 2019b, p. 190, grifo meu). Destaquei as palavras utilizadas pela própria autora por conta da sua objetividade em

\footnotetext{
${ }^{2}$ Silvia Federici diz: "Ao menos desde que os zapatistas, em 31 de dezembro de 1993, tomaram o zócalo [praça central] de San Cristóbal de las Casas, em chiapas, para protestar contra a legislação que dissolvia as terras ejidales [propriedades rurais coletivas] do México, o conceito de 'comuns' ganhou popularidade entre a esquerda radical, tanto internacionalmente quanto nos Estados Unidos, e apareceu como ponto de convergência entre anarquistas, marxistas/socialistas, ecologistas e eco feministas.// Há razões importantes para que essa ideia aparentemente arcaica tenha vindo para o centro da discussão [...], houve uma derrocada do modelo estatista de revolução, [...]. De outro, a tentativa neoliberal de subordinar toda forma de vida e conhecimento à lógica do mercado aumentou nossa consciência do perigo de viver em um mundo onde já não temos acesso a mares, árvores, animais e seres como nós, a não ser pela lógica do dinheiro. [...] // o conceito dos comuns ofereceu uma alternativa lógica e histórica ao Estado e à propriedade privada, bem como ao Estado e ao mercado[...]" (FEDERICI, 2019a, pp. 304-305).
}

TEIXEIRA, Nathan Menezes Amarante. Corpo, cotidiano e reprodução: considerações sobre o neoliberalismo a partir de Silvia Federici. Griot : Revista de Filosofia, Amargosa - BA, v.21 n.3, p.218-235, outubro, 2021. 
apontar aquilo que ela está propondo: a existência de uma ligação fundamental do corpo com a estrutura social na medida em que o processo de constituição desses corpos - seu modo de ser ambientado genericamente pela totalidade, a partir do qual as individualidades se constituem se mostra como uma estrutura acumulada/sedimentada que dispõe renovadamente as possibilidades de ser e fazer do corpo, acúmulo/sedimentação possíveis a partir das condições materiais e socialmente organizadas da vida.

Desde Calibã e a bruxa, por exemplo, essa abordagem mostra-se central para a autora, pois tratou-se ali de demonstrar o quanto a dimensão de reprodução corporal da existência em geral e a capacidade reprodutiva das mulheres em específico, foi colocada a serviço da acumulação do capital ao adquirir a função de reproduzir a mercadoria força de trabalho. Se posicionando contrariamente à ortodoxia marxista - apesar de realizar essa oposição dentro das bases do materialismo dialético marxista - que ignoraria o específico do modo de opressão das mulheres e simultaneamente não daria o devido valor à reprodução cotidiana da força de trabalho como sendo também um processo produtivo de valorização, Federici se volta para o momento de transição do feudalismo para o capitalismo para o examinar " [...] do ponto de vista das mudanças que introduziu na posição das mulheres e na produção da força de trabalho" (FEDERICI, 2017, p. 26). A conexão destes dois pontos, conforme ela explica em uma nota, consiste no fato de que " [...] no capitalismo a reprodução geracional dos trabalhadores e a regeneração cotidiana de sua capacidade de trabalho se converteram em um 'trabalho de mulheres', embora mistificado, pela sua condição de não assalariado [...]" (FEDERICI, 2017, p. 26).

Trata-se, fundamentalmente, de uma perspectiva que aponta que o processo de acumulação primitiva apresentado por Marx como responsável pela formação e acumulação da separação entre força de trabalho e meios de subsistência ${ }^{3}$, marcado pela expropriação dos trabalhadores europeus e pela escravização e colonização da América e da África, não foram os únicos métodos pelos quais o proletariado mundial foi formado. Igualmente de importância fundamental em todo este processo foi "[...] a transformação do corpo em uma máquina de trabalho e a sujeição das mulheres para a reprodução da força de trabalho" (FEDERICI, 2017, p. 119), ou seja, “[...] o corpo feminino foi transformado em instrumento para a reprodução do trabalho [...] tratado como máquina natural de criação, funcionando de acordo com ritmos que estavam fora do controle das mulheres" (FEDERICI, 2017, p. 178).

Segundo Federici, os processos de cercamentos da Europa do final do século $\mathrm{XV}^{4}$, coincidentes com a expansão colonial, marcaram uma desintegração da base comunitária de vida presente na Idade Média e impactou muito mais fortemente as mulheres do que os homens, que possuíam mais poder sobre a terra e mais poder social, de modo que as mulheres dependiam fortemente das terras comunais para garantir sua subsistência e exercitar formas de sociabilidade

\footnotetext{
${ }^{3}$ Especificamente no Capítulo XXIV do Livro I de O capital, que Marx analisa o processo de acumulação forçada das bases gerais de emergência e consolidação da produtividade capitalista, a desvinculação entre produtor e seus bens comuns de produção. Marx diz: "A relação capitalista pressupõe a separação entre os trabalhadores e a propriedade das condições de realização do trabalho. Tão logo a produção capitalista esteja de pé, ela não apenas conserva essa separação, mas a reproduz em escala dada vez maior. $O$ processo que cria a relação capitalista não pode ser senão o processo de separação entre o trabalhador e a propriedade das condições de realização de seu trabalho [...]. A assim chamada acumulação primitiva não é, por conseguinte, mais do que o processo histórico de separação entre produtor e meio de produção" (MARX, 2017, p.786).

4 "Desde o começo do capitalismo, a guerra e a privatização da terra empobreceram a classe trabalhadora. Este fenômeno foi internacional. Em meados do século XVI, os comerciantes europeus haviam expropriado boa parte das Ilhas Canárias para transformá-las em plantations de cana-de-açúcar. $O$ maior processo de privatização e cercamento de terras ocorreu no continente americano, onde, no início do século XVII, os espanhóis tinham se apropriado de um terço das terras comunais indígenas [...] // Na Europa, a privatização da terra começou no final do século XV, coincidindo com a expansão colonial . [...] Defino todos esses processos como expropriação da terra, porque, mesmo quando a força não era usada, a perda da terra se dava contra a vontade do indivíduo e da comunidade, solapando sua capacidade de subsistência." (FEDERICI, 2017, p. 130).
}

TEIXEIRA, Nathan Menezes Amarante. Corpo, cotidiano e reprodução: considerações sobre o neoliberalismo a partir de Silvia Federici. Griot : Revista de Filosofia, Amargosa - BA, v.21 n.3, p.218-235, outubro, 2021. 
junto a outras mulheres. Assim, ao mesmo tempo em que as terras eram cercadas, havia uma crise populacional a ser resolvida pelo Estado diante da necessidade colocada do novo sistema econômico nascente, momento em que se mostra fundamental o controle da reprodução da vida e do potencial reprodutivo da mulher", pois "a principal iniciativa do Estado [...] foi lançar uma verdadeira guerra contra as mulheres, claramente orientada a quebrar o controle que elas haviam exercido sobre seus corpos e sua reprodução" (FEDERICI, 2017, p. 174), isto travado fundamentalmente pela caça às bruxas. Portanto:

com o desaparecimento da economia de subsistência que havia predominado na Europa pré-capitalista, a unidade entre produção e reprodução, típica de todas as sociedades baseadas na produção-para-o-uso, chegou ao fim conforme essas atividades foram se tornando portadoras de outras relações sociais e eram sexualmente diferenciadas. No novo regime monetário, somente a produção-para-o-mercado estava definida como atividade criadora de valor, enquanto a reprodução do trabalhador começou a ser considerada como algo sem valor do ponto de vista econômico e, inclusive, deixou de ser considerada um trabalho [...] a importância econômica da reprodução da força de trabalho realizada no âmbito doméstico e sua função na acumulação do capital se tornaram invisíveis [...] (FEDERICI, 2017, p. 145).

E ainda:

[...] o corpo mecânico, o corpo-máquina, não poderia ter se convertido em modelo de comportamento social sem a destruição, por parte do Estado, de uma ampla gama de crenças pré-capitalistas, práticas e sujeitos sociais cuja existência contradiz a regulação do comportamento corporal (FEDERICI, 2017, p. 257).

O mais significativo destas considerações, para os propósitos específicos deste trabalho, consiste na colocação de Silvia Federici de que a procriação bem como a renovação diária das necessidades que vem junto à renovação de certos valores e modos de ser, é uma força produtiva fundamental para estabelecimento da sociabilidade, não é algo biológico e natural, mas produz e reproduz estruturas sedimentadas no corpo que renovam a organização da totalidade social condicionante. Essa dimensão é tão fundamental que foi base da acumulação capitalista onde coloca-se a reprodução para a produção, ambas são dissociadas na estruturação do corpo social como base do cercamento de terras, com a correlata estruturação do próprio corpo individual que vira função, vira força utilizada para uma produção radicalmente dissociada da reprodução deste corpo específico. Assim, compreende-se todo o processo de criminalização do controle da natalidade e dos métodos contraceptivos e abortivos utilizados pelas mulheres até então, junto com um processo de redução das mulheres a não-trabalhadoras, encerrando-as na função doméstica de fazer filhos e também como responsáveis integralmente da dimensão reprodutiva da vida sobre o qual se apoiavam os homens que trabalhavam. Ao mesmo tempo, os saberes femininos ${ }^{6}$ eram dizimados pois, na medida em que eram perspectivas de controle e organização não somente da sua própria dimensão reprodutiva mas igualmente sobre a dimensão geral da

\footnotetext{
5 "Enquanto na Idade Média elas podiam usar métodos contraceptivos e haviam exercido um controle indiscutível sobre o parto, a partir de agora seus úteros se transforam em território político, controlados pelos homens e pelo Estado: a procriação foi colocada diretamente a serviço da acumulação capitalista" (FEDERICI, 2017, p. 178).

6 "A criminalização do controle das mulheres sobre a procriação é um fenômeno cuja importância não pode deixar de ser enfatizada, tanto do ponto de vista de seus efeitos sobre as mulheres, quanto por suas consequências na organização capitalista do trabalho. [...] A criminalização da contracepção expropriou as mulheres desse saber, que havia sido transmitido de geração a geração, proporcionando-lhes certa autonomia em relação ao nascimento dos filhos" (FEDERICI, 2017, p. 181).
}

TEIXEIRA, Nathan Menezes Amarante. Corpo, cotidiano e reprodução: considerações sobre o neoliberalismo a partir de Silvia Federici. Griot : Revista de Filosofia, Amargosa - BA, v.21 n.3, p.218-235, outubro, 2021. 
reprodução da vida a partir da valorização de uma base material comum, representavam todo uma organização da sociabilidade marcada por uma racionalidade oposta àquela do capital e à divisão sexual patriarcal, posto que valorizando o ser material comum da reprodução e, por isso, voltado para a construção de um modo de vida outro.

É nesta ótica que ocorre uma diferenciação sexual correlata, pois o corpo do homem é colocado como algo a ser usado produtivamente pelo capital pois serve à produção de mais-valia. Por sua vez, o corpo da mulher vira corpo que serve para dar origem física à novos corpos-força de trabalho, renovando diariamente também a subsistência física e comportamental de um certo modo de ser que é resultado de um processo de valorização do corpo como objeto/propriedade de si mesmo passível de ser vendido como força produtiva, requisito fundamental do sistema capitalista e base acumulada para seu desenvolvimento.

Assim, é fundamental que seja destacado aqui o seguinte diagnóstico, possibilitado pela abordagem crítica feminista de Silvia Federici: a racionalidade da acumulação primitiva do capital se apresenta desde o início visando à domesticação do corpo e do comportamento individual para que as potencialidades deste se transformassem em força de trabalho, o que implica não só dispor as condições materiais de reprodução como meros meios para, mas também todo um modo específico de ser comportamental e que "requer diversos serviços emocionais e físicos que são de natureza interativa" (FEDERICI, 2021, p. 105) e que "nos reproduz nos valorando" (FEDERICI, 2019a, p. 18).

Trata-se então de se afirmar a necessidade de "[...] uma perspectiva e um movimento que confrontem o capitalismo com uma compreensão mais profunda das exigências da reprodução diária da vida [...]" (FEDERICI, p. 2021, p. 20, grifo meu), pois aí está dada a base material na qual renovamos diariamente as necessidades nas suas formas socialmente determinadas e sedimentadas no corpo e nos desenvolvemos como certos modos de ser relacionados a esta ambientação prático-corporal prévia. Isto mostra-se importante por resgatar o valor da dimensão reprodutiva da vida, chamando atenção para o fato de que não importa o que a ação produtiva dos indivíduos vá objetivar como uma nova possibilidade prática de efetivação de si agindo no seu meio, mas que há uma dimensão reprodutiva inelutável que renova todo o modo de ser corporal em certa totalidade social dada, renovação que é produtiva e valorativa na medida em que sedimenta ativamente, como possibilidade prática aberta, um certo modo de ser a partir do qual os indivíduos são possíveis tais como vieram sendo produzidos e reproduzidos em certa configuração social dada.

Por isso, inclusive, Federici coloca a "[...] reestruturação da reprodução como terreno crucial para transformar as relações sociais" (FEDERICI, 2021, p. 121). Novamente, mostrando a importância da reprodução em geral e no modo em que essa dimensão foi usada pelo capitalismo, Federici afirma: "Uma vez que a força de trabalho só pode existir no indivíduo vivo, sua reprodução deve ser simultaneamente uma produção e valorização das qualidades desejadas, assim como uma adaptação aos padrões de vida" (FEDERICI, 2019b, p. 209, grifo meu).

Entretanto, há ainda a importância de indicar-se a dimensão material comum da reprodução, ou, seja, para a característica de ser comum dos meios materiais de reprodução. Segundo a autora, uma das contribuições fundamentais da crítica feminista da qual ela parte consiste em, ao estabelecer uma política centrada no reconhecimento e importância da reprodução como garantia de sobrevivência e terreno prático ativo de resistência e início de uma transformação da organização social da vida, coloca que “[...] a reprodução é o pilar do "tecido social' [...]" (FEDERICI, 2019a, p. 269) na medida em que é a totalidade acumulada de condições técnicas $e$ de relações sociais sempre renovadas produtivamente e que transformam e organizam materialmente esse tecido que é a base de desenvolvimento de nossa sociabilidade. Portanto, o

TEIXEIRA, Nathan Menezes Amarante. Corpo, cotidiano e reprodução: considerações sobre o neoliberalismo a partir de Silvia Federici. Griot : Revista de Filosofia, Amargosa - BA, v.21 n.3, p.218-235, outubro, 2021. 
comum como qualificador desses meios materiais de reprodução - que comportam o grau de desenvolvimento técnico condicionante da produção econômica assim como as relações humanas nas quais indivíduos são constituídos intersubjetivamente em um entrelaçamento de ações diárias e valorativas - diz respeito, primeiramente, ao fato de que são objetivações na materialidade comum do tecido social, são possibilidades inscritas no modo específico de estruturação histórico desse tecido.

Além disso, temos outro ponto, dialeticamente ligado ao primeiro, que consiste na dimensão produtiva do comum, pois, estas objetivações estão na base material da totalidade social na mesma medida em que a produzem e a renovam materialmente. Neste sentido é importante esta consideração que demonstra que "fazer/pôr algo em/como comum" é um aspecto irredutível de nossa vida na perspectiva de um produzir e reproduzir a organização da base material de nossa vida social, a tecitura de generalidade como solo socializado produtivamente, bem como nos produz como indivíduos possibilitados a partir dessa generalidade social.

A partir destas considerações destaca-se igualmente a importância do cotidiano, pois, quando Federici pontua que "o trabalho reprodutivo [...] é a base material de nossa vida" (FEDERICI, 2019b, p. 196) está em questão a cotidianidade como o fundo comum sobre o qual se desenvolve toda existência individual, na medida em que a base social do existir é dada enquanto corpo se realizando a partir das condições materiais cotidianamente renovadas e que, por isso, sedimentam estruturas como modos de ser intersubjetivos. O cotidiano então é colocado como o "terreno das relações diárias e da reprodução" (FEDERICI, 2019b, p. 183), relações aí dadas como totalidade e que se mostram como "as fábricas sociais de nossas vidas" (FEDERICI, 2019b, p. 183). E vemos novamente a importância da abordagem materialista e feminista da autora: a divisão sexual instaura uma constituição de valores que são parte importante da estrutura social, ou, em outros termos, a dinâmica material da sociedade é vivida também a partir da socialização e disposição dos corpos sexualmente distinguidos, o que implica afirmar que o processo de valorização do que é "ser corpo" é importante para a constituição e manutenção da estrutura específica do tecido social, processo este que diz respeito à forma socialmente instituída da reprodução diária de nossas vidas

É ainda bastante significativo o fato de que Federici afirme, em um de seus textos, que essa sua consideração sobre a reprodução se ligue à perspectiva do cotidiano tal como sustentada por Henry Lefebvre, sociólogo marxista francês que se dedicou a desenvolver, pelas bases do materialismo dialético, o que ele chama de uma crítica da vida cotidiana, apresentada especificamente em três obras ${ }^{7}$. Assim, vejamos o que a própria Federici diz:

[...] Lefebvre argumentou que a teoria social deveria endereçar-se à vida do 'trabalhador por inteiro' e assim começar a investigar como a 'cotidianidade' é constituída e porque os filósofos constantemente a desvalorizaram. [...] // Entretanto, foi com a ascensão do movimento feminista que a 'crítica da vida cotidiana' se tornou a chave para essa compreensão abrangente da sociedade que Lefebvre estava buscando em sua obra. Rebelando-se contra o confinamento da mulher ao trabalho reprodutivo e às hierarquias construídas pela divisão sexual do trabalho, o movimento de mulheres forneceu uma base material para a crítica da vida cotidiana e trouxe à tona a 'estrutura profunda', o 'arco' que subjaz e mantém ligada a multiplicidade das ações diárias [...] (FEDERICI, p. 2019b, p. 175).

Segundo a passagem, Silvia Federici aceita a base geral da perspectiva de Lefebvre sobre o cotidiano, pontuando ainda o importante desdobramento que a abordagem feminista faz em

\footnotetext{
${ }^{7}$ Trata-se das obras Critique de la vie quotidienne I, II e III.
} 
relação à essa categoria de análise social, particularmente no fato de que lhe dá uma base material significativa. Para maiores desdobramentos disto, é importante recorrermos brevemente à proposta teórica de Lefebvre, a partir da ideia geral de que o terreno do cotidiano e suas relações é que "[...] acimentam [cimentent] desse modo a vida social [...]" (LEFEBVRE, 1977, p. 103). Colocar o cotidiano como base de ligação e solidificação material da totalidade social implica afirmar que:

[...] é na vida cotidiana e a partir dela que se realizam as verdadeiras criações, aquelas que produzem o humano e que produzem os homens no curso de sua humanização [...] // É na banalidade dos dias que o olho aprende a ver, o ouvido a escutar, o corpo a seguir os ritmos. [...] O mais importante, é notar que os sentimentos, as ideias, os estilos de vida, os prazeres se confirmam na cotidianidade (LEFEBVRE, 1980, p. 50).

Segundo Lefebvre, a cotidianidade mostrar-se-ia como o lugar fundamental de ligação da individualidade com a totalidade, pois seria o meio prático intermediador no qual processos historicamente condicionados se sedimentariam como relações sociais concretas a partir das quais os indivíduos tem significado no mundo, tem um lugar a partir do qual são socializados, na mesma medida em que o mundo social tem significado para eles, enquanto generalidade produzida e reproduzida pela atividade desses indivíduos. Há um "ritmo cotidiano" no qual o corpo segue, conforme a passagem, posto que o corpo seria um processo de vir a ser dependente da materialidade como o tecido socialmente instituído e sempre renovado no âmbito da vida cotidiana, um nível particularizado da totalidade no qual se abre as condições genéricas e individualizadas da vida. Desse modo, "objetos, gestos e palavras da vida cotidiana encarnam [incarnant] a totalidade [...]" (LEFEBVRE, 1980, p. 61), eles dão corpo ao modo de ser social, posto que é no cotidiano, como unidade dialética de produção e reprodução inerente à totalidade social, que o ser social é corporalmente possibilitado, no sentido tanto de dispor possibilidades materiais e hábitos constituintes do fazer humano que vai se renovando a partir da totalidade, quanto no de fazer vir a ser novamente possível essa totalidade por todo um conjunto diverso de práticas sedimentadas nos modos de ser. Então, “existem condições determinadas [...], históricas [...] que constituem" a materialidade do cotidiano, assim como "existem processos que contêm o vir a ser [le devenir] e as tendências [...]" do cotidiano, e, fundamentalmente, "condições e processos indicam possibilidades" (LEFEBVRE, 1980, p. 114, grifos do autor) produzidas e reproduzidas cotidianamente.

Nas palavras do autor:

\begin{abstract}
A noção de vida cotidiana só tem sentido em uma totalidade, mas em uma concepção dialética de totalidade. Para que ela corresponda à alguma coisa, é preciso e suficiente que a totalidade (a sociedade global, a estrutura social, a cultura, etc.) admita e contenha níveis. [...] Ela se define como um nível da prática social na totalidade" (LEFEBVRE, 1980, p. 36).
\end{abstract}

Temos assim a compreensão de que a totalidade social comportaria, como fundo material geral condicionante daquilo que vem a ser possível a partir dela e que a renova - a unidade dialética materialista de uma condição social genérica possibilitadora dos indivíduos e sendo possibilitada por eles -, um nível no âmbito da particularidade, o ponto específico e concreto no qual essa produção e reprodução da generalidade social $e$ dos modos de vida singulares ganham corpo através da prática. É no cotidiano que emergem os hábitos, as disposições afetivas, as representações e toda a ambientação prática dos modos de ser, que são processos contínuos de criação a partir de certas estabilidades sedimentadas condicionantes. A cotidianidade é uma 
estruturação contínua de um “[...] horizonte comum de experiência [...]" (HOA, 2014, p. 68), de possibilidades e de um "ritmo comum" de vir a ser, que solidifica nos diferentes níveis da existência a sociedade tal como veio vindo a ser, assim como solidifica o existir em uma estrutura social sempre por se fazer, e neste horizonte, se desenrola de diversos modos a dinâmica dialética de uma determinação genérica junto a uma autonomia parcial a partir da qual essa determinação é produzida e reproduzida.

As determinações cotidianas "[...] conservam uma unidade em um todo [...]" (LEFEBVRE, 1980 , p. 123), renovando esse nível da totalidade no qual o vir a ser e a mobilidade são dados a partir "[...] de uma situação relativamente estável no todo" (LEFEBVRE, 1980, p. 124). Tal unidade, portanto, "[...] é sempre uma unidade conflituosa $[. .$.$] por confrontar em si o social e o$ individual [...] [em que] o 'ser humano' vem a ser uma 'pessoa' [...] [em] um tecido de possibilidades pouco a pouco condensadas por escolhas" (LEFEBVRE, 1980, p. 71, grifos meus).

Então, se retornamos às considerações anteriores de Silvia Federici à luz de seu comprometimento com a compreensão de cotidiano de Henri Lefebvre, vemos que ela coloca a dimensão de reprodução da vida como o conjunto de atividades e forças que condicionam e são condicionados pela totalidade social em geral e sua dimensão propriamente econômica, que dão corpo cotidianamente às diversas relações humanas que nos produz e reproduz socialmente. A partir deste recorte, há no nível da produtividade da vida cotidiana a ação da práxis corporificada que produz e reproduz modos de ser socializados da vida humana - estrutura sedimentada de desejos, necessidades, a dimensão psíquica, comportamentos, a afetividade etc. - e por isso é uma forma de trabalho produtivo de valor, valora os indivíduos e a base produtiva-reprodutiva da tecitura social que condiciona $e$ é condicionada pela produção econômica e seu momento histórico de desenvolvimento tecnológico. Ou seja, a partir deste ponto de vista se torna "[...] possível reconhecer que a 'vida cotidiana' não é um complexo genérico de eventos, atitudes, e experiências buscando por uma ordem. É uma realidade estruturada, organizada ao redor de um processo de produção específico, a produção de seres humanos [...]" (FEDERICI, 2019b, pp. 175-176, grifos meus).

É o que leva Federici a afirmar que a reprodução da vida humana é algo que "[...] no capitalismo, está subordinada à reprodução da mão de obra e, portanto, sujeita à regulação estatal específica" (FEDERICI, 2021, p. 99). Visando desde seu surgimento, e de modo fundamental, a reprodução contínua de um modo de ser corporalmente moldado pela disciplina e pela racionalidade do trabalho assim como o barateamento contínuo dos custos dessa reprodução, e, por fim, visando tecer certos laços específicos de sociabilidade e uma estrutura de cotidianidade, o capital garante para si um trabalho reprodutivo que serve para isso: a reprodução da vida humana vira um lugar instrumentalizado, negativizado, alocado na família como centro próprio de reprodutividade segundo tal lógica, um trabalho não remunerado e, supostamente, de "natureza feminina". Em suma, tem-se a "[...] separação (característica da lógica e da história do desenvolvimento capitalista) entre produção e reprodução, bem como a naturalização desta última como "trabalho de mulheres" (FEDERICI, 2021, p. 137, grifo meu).

Visando apresentar estas considerações do modo mais objetivo possível, à luz dos desdobramentos seguintes, é preciso pontuar: há uma totalidade/tecido social, dentro da qual há um nível, o do cotidiano, no qual, como corpo, somos produzidos e reproduzidos através de uma " [...] estrutura acumulada de desejos e necessidades que tem sido a base de nossa reprodução social [...]" (FEDERICI, 2019b, p. 190), estrutura que também precisa ser continuamente reproduzida. $O$ cotidiano é por si só uma totalidade - subconjunto da totalidade social - que nos dá um horizonte comum material de possibilidades, no seu ponto de ligação/abertura à totalidade social, além de dar os modos de ser sedimentados no corpo. Então, a totalidade cotidiana também 
tem uma dimensão particularizada no que concerne ao social - determina e é determinada - onde uma série de atividades e relações são possibilitadas por certas tendências gerais que por sua vez precisam serem recriadas. Neste ponto há indeterminação, de onde algo novo sempre pode vir a ser, e o cotidiano, com essas divisões dialéticas internas, é o campo da produção e reprodução de uma força produtiva específica e que Federici chama de dimensão de reprodução da vida, na medida em que nos renova renovando nosso modo de ser tal como tendo vindo a ser possível no tecido social. É o que o capitalismo se apropriou para reproduzir para si força de trabalho e colocou como função das mulheres, tal como discutido em Calibã e a bruxa.

Assentada essa base argumentativa, outro ponto para desdobrarmos melhor a perspectiva de Federici, centrado na racionalidade da acumulação do capital, nos será dado se formos a algumas considerações de Rosa Luxemburgo. A existência de tal relação foi devidamente apontada, por exemplo, por Hernán Ouviña em seu livro Rosa Luxemburgo e a reinvenção da política, apontamento que aqui é tomado como base na mesma medida em que será desenvolvido algo diferente ${ }^{8}$.

Sem a pretensão de dar conta de toda a riqueza e possíveis desdobramentos atuais das considerações gerais próprias de Rosa Luxemburgo ou, em específico, de sua obra $A$ acumulação do capital que é tomada aqui como base de análise, o que temos como ponto de partida assumido por ela é a afirmação de que o capital sempre precisa de territórios e organizações sociais não subsumidas ainda à sua racionalidade econômica, algo outro de si, dos quais se apropria por uma constante desarticulação de suas formas de organização social. Assim, percebemos "[...] que o capitalismo está ligado [...] à existência coetânea de camadas e sociedades não capitalistas" (LUXEMBURGO, 2021, p. 262), de modo que se apresenta uma "contradição dialética: a acumulação capitalista necessita, para seu desenvolvimento, de um meio ambiente de formações sociais não capitalistas: avança em constante troca de matérias com elas [...]" (LUXEMBURGO, 2021, p. 363).

Colocando-se do ponto de vista da totalidade, ou seja, aquele a partir do qual o tecido social se mostra como um processo histórico de produção e reprodução do capital na medida em que suas formas concretas constituintes são os meios materiais pelos quais o valor se realiza e se amplia, Rosa Luxemburgo mostra que a questão que se apresenta é como garantir "que as condições do mercado", que oferecem ao capital força de trabalho, meios de produção privados e as relações de troca que realizam como dinheiro a mais-valia extraída da produção anterior, sempre estão novamente presentes correspondendo, "em cada caso, às necessidades de sua acumulação" (LUXEMBURGO, 2021, p. 34). Segundo a autora:

\begin{abstract}
A verdadeira finalidade e o impulso motriz da produção capitalista não é conseguir maisvalia em geral, numa só apropriação, em qualquer quantidade, mas de forma ilimitada, em quantidade crescente. Isso, porém, não pode realizar-se se não pelo meio mágico enunciado: pela produção capitalista, isto é, pela apropriação de trabalho assalariado não pago no processo de produção de mercadorias e pela sua venda )LUXEMBURGO, 2021, p. 27).
\end{abstract}

Visando dar conta das condições concretas historicamente renovadas, que instituíram a base da produção capitalista - a acumulação do capital pela pilhagem das terras comunais responsável

\footnotetext{
${ }^{8}$ Tal relação entre as duas pensadoras é estabelecida por Ouviña no capítulo 2 de seu livro supracitado, a partir da importância, para o pensamento de Silvia Federici, de Maria Mies e seu livro Patriarchy and Accumulation on a World Scale: Women in the International Division of Labour, publicado pela primeira vez em 1986, importância marcada pela própria Federici em livros como Calibã e a bruxa e $O$ ponto zero da revolução. Maria Mies, neste livro, afirma desde o prefácio a importância das considerações de Rosa Luxemburgo sobre a acumulação do capital para sua própria construção argumentativa.
} 
pela instituição material da "desvinculação entre o produtor e seus bens comuns de autossustento, de tal forma que se obtivesse uma espécie de 'separação' que tendesse a ser naturalizado pelas massas “despossuídas" (OUVIÑA, 2021, p. 60) -, Rosa apresenta a consideração de que este é um processo permanente e continuamente renovado, como expansão ilimitada da acumulação capitalista na mesma medida em que permite reestruturações periódicas do capitalismo como sistema mundial. Assim, a economia capitalista se instaura e se expande através da consolidação do mercado como centro da reprodução social, como articulador das diversas modalidades de intercâmbio humanas que passam a ser as possiblidades efetivas internas à determinada sociedade, que garantem a produção e a compra de seus produtos em forma capitalista junto à aquisição de seus elementos de produção, bem como do ponto de vista externo, onde tem-se "[...] a zona social não capitalista que absorve seus produtos e lhe fornece elementos de produção e operários" (LUXEMBURGO, 2021, p. 364), onde percebe-se um ímpeto intrínseco de dispor, como mero meio material inerte que só serve à sua autovalorização, o conjunto da vida social. Tal racionalidade, longe de ser "puramente econômica", visa continuamente a consolidação de relações sociais próprias à forma capitalista de exploração do trabalho, sistematicamente fazendo uso de todos os elementos externos a si para que prolongue a sua existência e continue não encontrando nenhum limite que não tenha sido colocado pelo seu próprio movimento de expansão.

Em suma, nas palavras de Rosa Luxemburgo:

Na acumulação primitiva, isto é, nos primórdios históricos do capitalismo na Europa, fins da Idade Média até a metade do século XIX, a libertação em massa dos camponeses constitui, na Inglaterra e no continente, o meio mais importante para se transformar maciçamente em capital os meios de produção e as forças de trabalho. Na política colonial moderna, porém, o capital realiza atualmente a mesma tarefa em escala muito maior. É uma ilusão esperar que o capitalismo se conforme com os meios de produção que pode obter pelo caminho do comércio de mercadorias. A dificuldade nesse ponto consiste em que, nas grandes zonas da superfície terrestre, as forças produtivas estão em poder de formações sociais que ou não se encontram inclinadas ao comércio de mercadorias ou não oferecem os meios de produção para o capital porque as formas econômicas ou a estrutura social constituem um obstáculo. [...] Por isso é que o capitalismo considera, como uma questão vital, a apropriação violenta dos meios de produção mais importantes dos países coloniais. [...] o método inicial do capital é a destruição e o aniquilamento sistemáticos das estruturas sociais não capitalistas. (LUXEMBURGO, 2021, p. 367).

Visando dar o devido destaque às estas considerações a partir dos propósitos desta pesquisa, é importante nos voltarmos ao comentário de Eduardo Barros Mariutti, segundo o qual um dos pontos centrais do pensamento de Rosa consiste na:

[...] caracterização do modo de produção capitalista como uma forma peculiar de reorganizar violentamente o conjunto da vida social em função da acumulação incessante de capitais. Definido desta forma, [...] o capital tem um ímpeto intrinsecamente expansionista, em um duplo sentido. $\mathrm{O}$ mais evidente fica patente na sua rápida e vigorosa capacidade de se alastrar geograficamente por todo o globo terrestre. Mas o segundo sentido é mais importante e, na realidade, conduz o primeiro: a acumulação capitalista está fadada a colonizar e ajustar à sua lógica todas as dimensões da vida social, inclusive as relações familiares e afetivas. É nesta acepção peculiar que o capitalismo se impõe progressivamente e contraditoriamente como uma forma universal que dissolve e se alimenta das relações sociais estranhas a ele. Logo, sua marca decisiva reside no seu impulso em desatrelar violentamente o trabalho dos meios de produção nas formas sociais com que ele se depara para, na sequência, poder incorporá-los ao seu metabolismo. (MARIUTTI, 2019, p. 3, grifos do autor)

TEIXEIRA, Nathan Menezes Amarante. Corpo, cotidiano e reprodução: considerações sobre o neoliberalismo a partir de Silvia Federici. Griot : Revista de Filosofia, Amargosa - BA, v.21 n.3, p.218-235, outubro, 2021. 
É fundamental, portanto, a indicação do comentador de que Rosa Luxemburgo tenha a preocupação em pontuar que há uma racionalidade de inclusão negativa de toda a totalidade social por parte do processo de acumulação capitalista na medida em que força uma determinada organização da vida e dos modos de ser em geral para que este âmbito sirva para, seja mero meio prático como um conjunto de atividades dominadas por uma necessidade exterior a elas que lhes impõem um fim a ser realizado. Tal determinação realiza uma inclusão negativa marcada fundamentalmente por uma dissolução de qualquer autonomia organizativa de laços sociais que também são constituintes das condições materiais do tecido social, mas uma dissolução que não suprime a existência concreta dessa região, pois esta precisa continuamente alimentar uma produtividade que só vem a existir e a se manter caso continue dispondo para si tais condições concretamente criadas e acumuladas. Tal racionalidade expande-se, fundamentalmente, por "todas as dimensões da vida social", está fadada a colonizar todas as regiões nas quais a sociabilidade humana se produz e reproduz diariamente, de modo a garantir a inclusão negativa ampliada não somente das condições técnicas do trabalho mas também as formas sociais das relações humanas.

A questão, portanto, a ser destacada consiste na presença desta perspectiva luxemburguista nas considerações de Silvia Federici sobre o corpo, a reprodução e o cotidiano apresentadas anteriormente. Ou seja, o que gostaria de sugerir como significativo para nossa discussão, consiste no fato de que Federici está mantendo tanto a dimensão da racionalidade da acumulação do capital de inclusão negativa desvalorizadora continuamente renovada da reprodução - reduzidas à uma totalidade cindida da unidade dialética produção/reprodução, pois vira meio para uma produção outra que dela "se alimenta" -, quanto o fato de que isso tende a se expandir por todo o tecido social. Porém, a filósofa italiana vai além, e este é o ponto central para nós, ao marcar que há fundamentalmente uma lógica de inclusão negativa expansiva na racionalidade de acumulação recorrente do capital da dimensão de reprodução da vida condicionante e condicionada da estrutura social, que nos atinge no corpo posto que é como corpo que estamos inseridos na totalidade a partir da cotidianidade. Em suma, a acumulação do capital sempre esteve e está interessada em fazer da reprodução socializada da vida humana, que se renova cotidianamente a partir da sua inserção particular no todo, o terreno sempre dissolvido, instrumentalizado e negado a partir do qual há a acumulação e reprodução de certo modo de ser - como corpo $e$ como tendo certa generalidade ambientadora cotidiana de vida - uma "força de trabalho". Logo, podemos "enxergar a reprodução da vida humana e da força de trabalho, bem como as hierarquias de gênero erguidas sobre ela, como elementos-chave do processo de acumulação" (FEDERICI, 2021, p. 152), e que, inclusive, falta nas abordagens marxistas tradicionais, tal como continua faltando nas considerações sobre o cotidiano de Lefebvre.

Dessa forma, podemos precisar melhor a especificidade das considerações de Silvia Federeci. Segundo a autora, a estrutura de relação instaurada e sempre novamente recolocada pela lógica de acumulação expansiva capitalista, além da dimensão propriamente econômica, que consiste em certos meios de produção, técnicas e organizações do trabalho e determinadas relações de organização internas ao processo produtivo pela contínua recolocação da "[...] separação entre os trabalhadores e a propriedade das condições de realização do trabalho [...]" (MARX, 2017, p. 786), também se apresenta pela recolocação das relações que nos formam e nos valoram cotidianamente tal como enquadradas nesta lógica capitalista. Por isso a afirmação de que o desenvolvimento capitalista é também o desenvolvimento de certas capacidades humanas e relações especificas "[...] que, por sua vez, geram ideologias, interesses e subjetividades que constituem uma força social destrutiva" (FEDERICI, 2021, p. 118). Portanto, se em termos 
marxistas tradicionais pode-se dizer que o capitalismo "[...] é um modo de produção da vida social que se caracteriza pelas forças produtivas que suscita e mobiliza e pelas relações de produção sobre as quais se assenta" (COGGIOLA, 2021, p. 13), Federici acrescenta, a partir de seu recorte específico, que essas forças produtivas estruturantes do social não são somente forças produtivas técnicas organizadoras de um modo de produção, mas que há, como base produtora/reprodutora da sociabilidade, a reprodução cotidiana da vida e de nós enquanto seres sociais ambientados por um fundo comum, e que, portanto, também participa do modo de produção em geral e, sob o capitalismo, serve ao lado do processo de trabalho à valorização do valor.

Compreende-se assim todas as implicações da afirmação de Silvia Federici sobre Marx de que:

[...] embora ele não tenha se concentrado muito nas destruições produzidas pela organização capitalista do machismo e do racismo e tenha prestado pouca atenção à transformação na subjetividade do proletariado, ainda assim ele compreendeu que precisamos de uma revolução para nos libertar não apenas das barreiras externas, mas da internalização da ideologia e das relações capitalistas [...] (FEDERICI, 2021, p. 123, grifos meus).

Em suma, o processo de internalização e reprodução de relações capitalistas é a própria constituição da subjetividade segundo a organização capitalista da vida cotidiana tal como entendida anteriormente, onde a lógica capitalista operou e continua operando uma transformação subjetiva. Logo, é preciso uma revolução neste domínio que, conforme visto, é certo nível estruturante do social $e$ das condições de possibilidade e transformação da subjetividade.

Todas essas considerações acima formam os quadros teóricos a partir dos quais a autora critica o neoliberalismo. Porém, antes da lida direta com este ponto, cumpre realizarmos um diálogo com Simone de Beauvoir. Assim, de modo bastante resumido, temos que, para Beauvoir, a subjetividade é movimento espontâneo e sensível aberto ao fora de si, que se vincula àquilo que lhe é outro para se realizar e se constituir. Esse movimento é livre posto que não encontra uma determinação anterior que condicione de maneira fechada seu fazer posterior. Por isso Beauvoir afirma que a liberdade é "a modalidade mesma da existência que [...] retoma por sua conta tudo que lhe vem do exterior" (BEAUVOIR, 2015, p 710), ou seja a subjetividade é o processo contínuo de interiorização do seu fora de si assim como um exteriorizar como certo modo de se fazer ser. $\mathrm{O}$ movimento livre do existir que é o sujeito e que o faz ser enquanto "constitutivamente orientado para outra coisa que não ele mesmo [constitutivement orienté vers autre chose que lui-même]" (BEAUVOIR, 2013, p. 219), se dá fenomenalmente como presença situada na medida em que se abre ao mundo vinculando-se a ele ambiguamente pois recebe certa parcela de ser interiorizada na mesma medida em que está distanciado por certa parte de indeterminação que ele introduz enquanto processo de nadificação.

Assim a subjetividade como liberdade é um "[...] movimento concreto e singular" (BEAUVOIR, 2013, p. 34) que se realiza como presença e " $[\ldots]$ adquire no mundo sua figura carnal e real [sa figure charnelle et réelle]" (BEAUVOIR, 2013, p. 168) e ao mesmo tempo se distancia parcialmente deste vínculo que a presença realiza para se recuperar no porvir. Este processo contínuo de se investir no mundo e dele se afastar para se escolher como novo investimento no porvir é então definido por Beauvoir deste modo: "a meta visada por minha liberdade, é conquistar a existência através da espessura sempre faltosa do ser [l'épaisseur toujours manquée de l'être]" (BEAUVOIR, 2013, p. 40, grifo meu). O momento do enraizamento da liberdade na situação é sua participação na espessura primeira do mundo, um "se misturar praticamente" às coisas que lhe dá a textura mundanamente situada do ser. Porém, há também um distanciamento desta por parte da liberdade quando tal espessura se faz faltosa, precisando

TEIXEIRA, Nathan Menezes Amarante. Corpo, cotidiano e reprodução: considerações sobre o neoliberalismo a partir de Silvia Federici. Griot : Revista de Filosofia, Amargosa - BA, v.21 n.3, p.218-235, outubro, 2021. 
ser recuperada no porvir, onde a liberdade se lança em direção ao ser enquanto aquilo que se conquista através do mundo, refazendo novamente o solo de onde o ser continuamente se desvela. Ou seja, a situação como espessura sensível socialmente constituída seria o solo que nutre a existência da subjetividade e do ser desvelado, de modo que toda abertura indeterminada de possíveis que a vontade humana realiza só é feita enquanto transformação das condições presentes da própria situação, então "[...] é a partir de um certo enraizamento [enracinement] singular no mundo histórico e econômico que esta vontade se lança em direção ao porvir [...] (BEAUVOIR, 2013, p. 25, grifo meu).

Uma vez que o enraizamento indica uma relação de determinação ambígua entre subjetividade e situação, uma relação material entre corpo e espessura sensível que faz desta última a materialidade fenomenal situada historicamente, colocar uma materialidade da qual a atividade humana depende não é oferecer um ser a priori que naturalmente lhe determinaria de modo mecânico, justamente pelo fato de que essa materialidade é dada a partir do processo contínuo e indeterminado da efetivação prática da subjetividade que a faz na mesma medida em que faz suas condições. Ou seja, segundo Simone de Beauvoir, nossa liberdade ontológica se realiza como presença a partir do comprometimento prévio na textura do ser, um vínculo que é de ordem eminentemente sensível. Portanto, a carne é o que se apresenta como o laço ontológico-ambíguo que une e separa a materialidade corpórea do sujeito e a camada genérica situada do ser. Essa ligação em uma separação realiza a abertura fenomenal da presença e situa a liberdade, fornecendo um solo material de constituição, justamente pelo fato de que essa liberdade se realiza primeiramente como espontaneidade sensível/corpórea que se encarna na carne genérica do mundo. A ambiguidade fundamental do existir humano como movimento livre aberto ao fora de si, se apresenta a partir do vínculo entre duas materialidades entrelaçadas ambiguamente - uma dependente da outra, sendo feita e formada pela outra -, o corpo do sujeito como presença sensível e prática, e a espessura da sua situação tal como constituída social e historicamente na qual "está engajada sua própria carne [est engajée sa propre chair]" (BEAUVOIR, 2013, p. 305), esta última sendo o vínculo ambíguo entre o devir corporificado do sujeito e a concretude objetiva do mundo.

Se a presença concreta e singular é a realização contínua de um vínculo sensível que une e separa subjetividade e mundo, este último como a espessura sensível genérica que determina e é determinada pela atividade prática da primeira, então outra dimensão importante da ambiguidade que se destaca é a da relação entre singularidade e totalidade. Segundo Simone de Beauvoir, a objetividade da situação como solo material historicamente constituído, é algo que sustenta e é sustentada pelo devir singular corpóreo que aí se realiza, de modo que a tensão ambígua da presença indica que sempre há uma singularização da totalidade junto à simultânea totalização do singular: em suma, há certa objetividade dada que é parcialmente independente da subjetividade e que é seu solo de possibilidade e desvelamento, assim como há uma subjetivação no modo em que esta espessura genérica dada é assumida pela transcendência prática e corporificada que é a subjetividade. Conforme a própria autora afirma:

[...] a ideia de liberdade não é incompatível com a existência de certas constantes. [...] há em toda história singular dados que ninguém sonha em negar a generalidade: a situação e as condutas se repetem; é no seio da generalidade e da repetição que brota o momento da decisão. [...] do fato da identidade da situação existencial através de todos os existentes e da identidade da facticidade que eles vão enfrentar, as significações se desvelam da mesma maneira à diversos indivíduos (BEAUVOIR, 2016, p. 91).

A importância desta passagem consiste precisamente na indicação da ambiguidade presente na relação entre devir livre prático - a subjetividade - e sua situação enquanto lugar na

TEIXEIRA, Nathan Menezes Amarante. Corpo, cotidiano e reprodução: considerações sobre o neoliberalismo a partir de Silvia Federici. Griot : Revista de Filosofia, Amargosa - BA, v.21 n.3, p.218-235, outubro, 2021. 
espessura social tal como determinada historicamente, a partir da qual se desdobra o vínculo entre singularidade e totalidade. Assim, há sempre uma generalidade/totalidade como espessura sensível comum que cria as mesmas "facticidades" que desvelam os possíveis para os indivíduos, que realizam o desenvolvimento material da sociedade e suas constantes a partir das quais individualidades são possíveis, e a tensão ambígua nunca resolvida é justamente a de uma ligação não qual nenhum dos dois lados existe sem o outro.

Portanto, o que gostaria de propor é pensarmos a ontologia materialista do corpo apresentada por Simone de Beauvoir como pano de fundo a partir do qual as considerações anteriores de Federici também podem ser colocadas. Assim, a relação anteriormente estabelecida pela filósofa italiana de que o corpo é valorado e reproduzido segundo estruturas sedimentadas na reprodução cotidiana, algo que por si só coloca ao menos indiretamente a questão do modo de ser do corpo, ganha maior concretude quando pensamos que está em jogo uma "[...] infraestrutura ontológica [...] " (BEAUVOIR, 2016, p. 103) determinante do movimento do existir humano que coloca que esse vir a ser corporificado precisa se relacionar ao que é outro de si para se constituir, precisa ser possibilitado a partir de um solo no qual encontra-se enraizado. Algo que se liga sem dificuldades à afirmação de Federici destacada no início do texto de que o corpo se forma expandindo-se para o que está "fora", e que pode ainda ser complementada pela colocação de que há "[...] uma interação constitutiva entre nossos corpos e um "exterior" (FEDERICI, 2019b, p. 190, grifo meu). O “ter as raízes" na situação, se pensarmos que esta é uma particularidade que adquire certa independência da totalidade mas ao mesmo tempo a sustenta e é sustentada por ela materialmente, se daria então no nível do cotidiano, tal como Federici assume de Lefebvre, de modo que "as pretensões ontológicas do existente assumem uma forma concreta segundo as possibilidades materiais que se lhe oferecem" (BEAUVOIR, 2016, p. 107) através das condições comuns e cotidianamente produzidas e reproduzidas da existência.

Em suma, o fundamental de tomarmos as considerações de Silvia Federici como condizentes com a ontologia ambígua de Simone de Beauvoir consiste em podermos objetivar: há uma condição materialista do modo de vir a ser possível dos indivíduos, na medida em que são fundamentalmente corpos que se valoram em interação a partir de uma textura/tecido social que eles produzem e reproduzem na mesma medida em que nela são produzidos e reproduzidos. Então, o conjunto de práticas e modos de ser em comum que são "[...] o fundamento de todo sistema político e econômico [...]" (FEDERICI, 2019a, p. 17) e que emergem no tecido social a partir do nível do cotidiano se dá pelo fato de termos aí o vínculo ambíguo de enraizamento do modo de ser do corpo.

O vínculo ambíguo que une separando - e que é uma relação dialética tensionada, nunca resolvida, segundo Beauvoir - o corpo à totalidade social se dá mediado pelo enraizamento na particularidade situada do cotidiano, essa estrutura sedimentada e sedimentadora de um processo de produção específico, conforme colocado por Federici anteriormente. Isto mostra-se também, portanto, no vínculo ambíguo entre o desenvolvimento técnico como um determinado modo de produção estruturante da textura social e, portanto, da base material de relações humanas e modos de ser, assim como essa base material que produz e reproduz os modos de ser sociais continua sustentando cotidianamente o desenvolvimento técnico dos modos de produção. Por fim, trata-se da possibilidade de assumirmos diretamente e como significativo o pano de fundo ontológico do corpo e da reprodução cotidiana tal como esteve subjacente às considerações de Silvia Federici, porém agora objetivando propriamente que há na base um vínculo dialético tensionado de enraizamento produtivo/reprodutivo.

Assim, tomando as considerações anteriores de Federici sobre a racionalidade de acumulação do capital, já marcadas pela compreensão específica da cotidianidade e do 
enraizamento do corpo conforme foi discutido, podemos nos voltar para suas considerações sobre o neoliberalismo. Segundo a autora, na medida em que a acumulação primitiva é um fenômeno constitutivo das relações capitalistas continuamente renovadas, então devemos pensar que a forma de inclusão negativa da base de produção/reprodução da vida que a cinde e a faz mera reprodução da produtividade exterior do capital, é "[...] algo que deve ser continuamente recolocado em ato, especialmente em tempos de crises capitalistas, quando relações de classe são modificadas e precisam adquirir novas bases" (FEDERICI, 2019, p. 16). Desse modo, a fase neoliberal do capitalismo estaria marcada pela radicalização desta racionalidade que lhe é constitutiva, realizando uma "[...] financeirização da reprodução [...]" onde "[...] novos lugares de acumulação de capital" (FEDERICI, 2019b, p. 62) se tornam possíveis. Essa financeirização do cotidiano, o ponto de junção dialética entre a produtividade dos modos de ser corporificados e a força produtiva estruturante da economia, é que teria sido central para a organização da totalidade do ser social propícia à lógica do capital financeiro, assim como a constituição de práticas cotidianas que promovem modos de ser que encarnam e renovam tal racionalidade financeira.

Segundo a autora, o pilar da reorganização estrutural neoliberal da economia capitalista global para superar a crise dos anos $1970^{9}$, possibilitou, fundamentalmente, uma "desterritorialização do capital e a financeirização das atividades econômicas [...]" (FEDERICI, 2019a, p. 212), de modo a permitir a abertura de novas áreas de liberdade de mercado. Verifica-se aí o quanto o movimento de acumulação do capital se efetiva a partir da forma do capital financeiro, que busca a expansão de áreas de especulação nas quais a valorização do capital pode ocorrer com a ampliação dos lucros sem os limites impostos pela produção. Assim, a forma financeira adotada pela crise marca a financeirização das economias, em que "testemunhamos o desinvestimento sistemático do Estado na reprodução da força de trabalho, implementado por meio de programas de ajus

te estrutural e pelo desmantelamento do "Estado de bem-estar social"' (FEDERICI, 2019a, p. 213), e tal fase de expansão capitalista requer a subordinação de qualquer atividade produtiva a esta lógica, e, "como resultado, surgiram uma política e uma ideologia que ressignificam os trabalhadores como microempresários, responsáveis por seu auto investimento [...]" (FEDERICI, 2019a, p. 163),

Por fim, Silvia Federici afirma que "[...] as atividades reprodutivas foram reorganizadas na forma de serviços produtores de valor que os trabalhadores devem comprar [...]" (FEDERICI, 2019a, p. 208), de modo que a "[...] "reprodução" é apresentada como um "investimento de si" (FEDERICI, 2019b, p. 64). Portanto, Federici está afirmando que o neoliberalismo mantém a racionalidade estruturante do capital de dispor para si toda a malha produtiva do tecido social a organização técnica do trabalho segundo a dinâmica própria ao modo de produção $e$ a produção cotidiana de um horizonte geral de modo de vida que torna possíveis certos modos de ser - só que com a especificidade de que a especulação financeira realizada em cima das atividades de reprodução social deram-se pela ampliação de recursos sociais disponíveis para utilização pelas finanças do mercado global, o que significa na prática, por exemplo, que “[...] os subsídios com cuidados de saúde, educação, pensões e transporte público foram todos cortados, [...] de forma

\footnotetext{
${ }_{9}^{9}$ David Harvey apresenta em $O$ neoliberalismo: história e implicaçães, uma análise mais propriamente econômica desta relação comentada aqui, que também encontramos em Silvia Federici com o acréscimo e destaque dado a toda esta discussão da reprodução e do cotidiano que veio aqui sendo comentada. Deste modo, a base das considerações neste trabalho sobre este ponto específico da financeirização neoliberal encontram-se em ambos os autores. Harvey chega, inclusive, a falar de um processo econômico de financeirização da economia e do cotidiano de modo que " [...] temos que examinar [...] as qualidades da experiencia cotidiana a fim de melhor identificar as bases materiais da construção do consentimento" (HARVEY, 2011, p. 50) ao neoliberalismo. Para maiores detalhes ver capítulos 1 e 2 desta obra citada.
}

TEIXEIRA, Nathan Menezes Amarante. Corpo, cotidiano e reprodução: considerações sobre o neoliberalismo a partir de Silvia Federici. Griot : Revista de Filosofia, Amargosa - BA, v.21 n.3, p.218-235, outubro, 2021. 
que cada articulação da reprodução da força de trabalho foi transformada em ponto de acumulação imediata"10 (FEDERICI, 2019a, p. 213).

Além disso, a outra especificidade neoliberal se dá no fato de que ampliação da racionalidade normativa desestabiliza a base renovada cotidianamente da vida, a coloca mais diretamente e mais entregue à situação "estar à serviço do capital", o que significa, primeiramente, deixar submetida à instabilidade e flutuações a base material ambientadora do modo de ser, as condições basilares e sedimentadas da reprodução cotidiana de nós mesmos. Por sua vez, tem-se também o fato de que, uma certa subjetividade emergirá desse solo marcada por uma compreensão de si condizente com esse modo de ser cotidianamente renovado, ou, poderíamos dizer, há uma radicalização da subjetivação a partir das bases e "ritmos" do vir a ser cotidiano que, na medida em que está mais entregue ao capital, acaba sedimentando e valorando os indivíduos de modo que eles mesmos se apresentem como a própria forma do capital.

Compreende-se, portanto, a estruturação política - disposição do Estado e da sociedade a partir dessa perspectiva - $e$ ideológica - modo de representação organizador $e$ organizado, produtor $e$ resultado do solo cotidiano de vida - que Silvia Federeci mencionou em uma passagem destaca acima como própria ao neoliberalismo, destacando-se a produção de um modo de ser da subjetividade marcado pela compreensão de si mesmo como microempresário que obtém uma "boa" reprodução da vida como resultado de um investimento especulativo prévio. Deste modo, a lógica do investimento especulativo que flutua e está sempre sujeito à riscos tece a base da organização econômica do social, dando as determinantes reguladoras da particularidade de cada um e, mais concretamente, o seu modo de vida cotidiano - seu solo de enraizamento, seguindo com Beauvoir - pois "investe" mais diretamente nesse ponto de acumulação. Ainda, essa racionalidade que centraliza um "si" como lugar de investimento capitalizável para comprar o próprio vir a ser cotidiano, é encarnada em modos de ser, qualidades e capacidades afinados aos padrões de vida dados, garantindo assim, do ponto de vista da produção de nós mesmos como humanos, a renovação diária da racionalidade econômica. Por fim, envolvendo todo o cotidiano e a base das práticas reprodutivas dos indivíduos, o neoliberalismo marca a generalização por todas as dimensões dessas práticas reprodutivas cotidianas, mesmo aquelas não diretamente dependentes da organização Estatal e desestabilizadas pela especulação. Ou seja, a inclusão negativa do modo de ser do indivíduo, sua subjetividade, se radicaliza pelo fato de que todo um conjunto de atividades cotidianas e de produção e reprodução de si, virão enquadradas pela lógica da instabilidade e do "si" como resultado de investimento, como algo capitalizável.

Compreendido assim o posicionamento teórico de Silvia Federici acerca do neoliberalismo, podemos finalizar a discussão com as considerações que ela faz acerca da organização de um projeto político em torno do comum. Como vimos, Federici mostra a dimensão da reprodução da existência como marcada por um vínculo dialético, uma dimensão cotidiana de produção e reprodução na qual um modo de ser é sedimentado em nós por ter sido tornado possível e por ser também possibilitador deste horizonte e "ritmo" comum do cotidiano. Como argumentei, a filósofa dá destaque ao corpo de tal modo que podemos dizer que é justamente por conta do corpo como base material ligada dialeticamente à materialidade do tecido social - o vínculo de enraizamento oferecido pelo diálogo com a ontologia materialista de Simone de Beauvoir -, que a dimensão da reprodução diária e em comum se apresenta como uma força produtiva específica e basilar para qualquer modo de produção econômico, condicionando e sendo condicionado por ele.

\footnotetext{
10 Para detalhamento da relação entre a crise financeira de 1970, a financeirização das economias, o crescimento da especulação em desfavor da produção e, consequentemente, a busca pela ampliação de recursos disponíveis à aplicação financeira global ver MOLLO, Maria de Lurdes Rollemberg. "Crédito, capital fictício, fragilidade financeira e crises: discussões teóricas, origens e formas de enfrentamento da crise atual" In. Economia e Sociedade, Campinas, v. 20, n. 3 (43), p. 449-474, dez. 2011.
}

TEIXEIRA, Nathan Menezes Amarante. Corpo, cotidiano e reprodução: considerações sobre o neoliberalismo a partir de Silvia Federici. Griot : Revista de Filosofia, Amargosa - BA, v.21 n.3, p.218-235, outubro, 2021. 
Silvia Federici afirma então a necessidade de mobilização de uma racionalidade, hábitos e modos de ser que, oriundos de $e$ voltados para o "[...] terreno de nossas relações diárias e de reprodução [...] [e visando] reconstituir a fábrica social de nossas vidas [...]" (FEDERICI, 2019b, p. 183), afirmem fundamentalmente a "[...] produção de nós mesmos como um sujeito comum" (FEDERICI, 2019b, p. 110). Segundo a autora:

[...] comuns são tanto os objetivos quanto as condições de nossa vida cotidiana e nossas lutas. Em uma forma embrionária, eles representam as relações sociais que nós gostaríamos de alcançar, assim como os meios para sua construção Eles não são lutas separadas mas uma perspectiva que trazemos à cada luta e à cada movimento social no qual nós participamos (FEDERICI, 2019b, p. 185, grifos meus).

A partir das citações acima, e retomando toda a discussão anterior, temos o seguinte conjunto de considerações: primeiro, há uma unidade dialética no fato de comum ser objetivo $e$ ser condição da vida cotidiana, o que significa que é comum a base material de produção e reprodução cotidiana de nossa vidas e modos de ser, mas esse comum é também o objetivo na medida em que é o que, visado positivamente através das lutas, se concretiza com as condutas comprometidas com sua efetivação; aqui, em segundo lugar, temos a unidade dialética das lutas que buscam o comum a ser objetivado na medida em que afirma a base comum de produção e reprodução do solo cotidiano. $O$ mesmo tipo de vínculo dialético observamos na afirmação de que essa totalidade parcialmente isolada, "ter uma base comum cotidiana que é mantida e afirmada nas lutas", é o fim visado, o princípio norteador do modo de estruturar a produção e reprodução, mas, ao mesmo tempo, ele já deve estar corporificado nos modos de ser presentes que formam e são formados nessas relações. Por isso a importância de nos "afirmarmos/produzirmos" como sujeitos comuns, ou seja, mobilizar ideal e praticamente a afirmação de que é a partir de uma determinada prática coletiva que os sujeitos se constituem como comunidade ativa e simultaneamente instituem os espaços comuns a partir dos quais eles se encontram vinculados e responsáveis pela sua manutenção, onde o comum é solicitado a partir das práticas cooperativas nas quais os indivíduos se engajam e se formam como comuns.

Tais considerações sobre o comum são breves indicações teóricas de Federici acerca da importância de afirmação desta dimensão e de sua lógica respectiva, a partir da sua base de compreensão do corpo e da reprodução cotidiana da vida como uma dimensão produtiva basilar da totalidade social e de nós mesmos, subsumida negativamente e de modo contínuo ao movimento de acumulação do capital até a sua interiorização subjetiva contemporânea no neoliberalismo e todas as implicações acima discutidas. $O$ ponto de vista feminista do qual ela parte possibilita não somente chamar a atenção para a importância desse âmbito produtivo que, como nível cotidiano na totalidade, produz e reproduz os modos de ser como base de organização da sociabilidade, e que foi subjugado à dimensão econômica na sua forma capitalista, mas como também e principalmente, chama a atenção para a hierarquia que foi estabelecida internamente à essa região ao ser qualificada negativamente, estruturada como base não remunerada do capital e como supostamente um "lugar natural" das mulheres. 


\section{Referências}

BEAUVOIR, Simone de. Pour une morale de l'ambiguité suivi de Pyrrhus et Cinéas. Paris: Gallimard, 2013.

BEAUVOIR, Simone de. Le deuxième sexe. Vol. I et II. Paris: Gallimard, 2016.

BEAUVOIR, Simone de. La force d l'âge. Paris: Gallimard, 2015.

COGGIOLA, Osvaldo. Teoria econômica marxista: uma introdução. São Paulo: Boitempo, 2021.

FEDERICI, Silvia. Calibã e a bruxa: mulheres, corpo e acumulação primitiva. São Paulo: Editora Elefante, 2017.

FEDERICI, Silvia. O ponto zero da revolução: trabalho doméstico, reprodução e luta feminista. São Paulo: Editora Elefante, 2019a.

FEDERICI, Silvia. Re-enchanting the world: feminism and the politics of the Commons. Califórnia: PM Press, 2019b.

FEDERICI, Silvia. Beyond the periphery of the skin: rethinking, remaking and reclaiming the body in the contemporary capitalism. Califórnia: PM Press, 2020.

FEDERICI, Silvia. O patriarcado do salário vol. I. São Paulo: Boitempo, 2021.

HARVEY, David. O neoliberalismo: história e implicações. São Paulo: Edições Loyola, 2014. HOA, Jen Hui Bon. "Totality and the common: Henri Lefebvre and Maurice Blanchot on everyday life" In. Cultural Critique, v. 88, pp. 54-78, fall, 2014.

KRUKS, Sonia. Simone de Beauvoir and the politics of ambiguity. Oxford: Oxford University Press, 2012.

LEFEBVRE, Henri. Critique de la vie quotidienne I. Introduction. Paris: L'arche Editeur, 1977. LEFEBVRE, Henri. Critique de la vie quotidienne II. Fondements d'une sociologie de la quotidienneté. Paris: L'arche Editeur, 1980.

LEFEBVRE, Henri. Critique de la vie cotidienne III. De la modernité au modernisme (Pour une métaphilosophie du quotidien. Paris: L'arche Editeur, 1981.

LUXEMBURGO, Rosa. A acumulação do capital. Rio de Janeiro: Civilização Brasileira, 2021.

MARIUTTI, Eduardo Barros. "Para além do economicismo: a acumulação de capital na perspectiva de Rosa Luxemburgo". In. Revista Novos Rumos, v. 56, n. 1, pp. 1-23, junho, 2019.

MARX, Karl. O capital. Livro I. São Paulo: Boitempo Editorial, 2013.

MIES, Maria. Patriarchy and Accumulation on a World Scale: Women in the International Division of Labour. London: Zed Books, 2014.

MOLLO, Maria de Lurdes Rollemberg. "Crédito, capital fictício, fragilidade financeira e crises: discussões teóricas, origens e formas de enfrentamento da crise atual" In. Economia e Sociedade, Campinas, v. 20, n. 3, p. 449-474, dez. 2011.

OUVIÑA, Hernán. Rosa Luxemburgo e a reinvenção da política. São Paulo: Boitempo, 2021.

Autor(a) para correspondência / Corresponding author: Nathan Menezes Amarante Teixeira. nathanmateixeira@gmail.com 